\title{
MEIOS ALTERNATIVOS DE RESOLUÇÃO DE CONTROVÉRSIAS (ADR / ODR) E MITIGAÇÃO DA LITIGÂNCIA NA PERSPECTIVA DO NOVO CÓDIGO DE PROCESSO CIVIL: UM CAMINHO MAIS CURTO RUMO À ORDEM JURÍDICA JUSTA?
}

\section{ALTERNATIVE DISPUTE RESOLUTION ( ADR / ODR ) AND MITIGATION OF LITIGATION IN THE CONTEXT OF THE NEW CODE OF CIVIL PROCEDURE: A SHORTER PATH TO FAIR LEGAL SYSTEM?}

\author{
${ }^{1}$ Leandro André Francisco Lima \\ ${ }^{2}$ Francisco Benedito Fernandes
}

\section{RESUMO}

O presente estudo aborda o emprego dos métodos alternativos de resolução de controvérsias (ADR's) na perspectiva do Novo Código de Processo Civil, tendo como referencial teórico a noção de Acesso à Justiça como direito à ordem jurídica justa. Indaga-se quanto às possibilidades de utilização pela jurisdição das ferramentas virtuais de resolução alternativa de controvérsias (ODR's), proporcionadas pelas tecnologias da informação, para maximização dos efeitos atinentes àquele direito. Vislumbra-se a pertinência deste questionamento tendo em mira a ampla adesão da sociedade à vida virtual. Emprega-se o método hipotético-dedutivo. A pesquisa é teórica, bibliográfica e documental.

Palavras-chave: Meios alternativos de resolução de controvérsias, Código de processo civil, Acesso à justiça

\begin{abstract}
This study addresses the use of Alternative Dispute Resolution (ADR's) methods, owing to the new Civil Law Procedure Code, having as it's theoretical framework the concept of access to justice as a Right to a fair Law system. It's asked about the possibilities of using the alternative Online Dispute Resolution (ODR's) tools by jurisdiction, provided by the information technology, in order to maximize the effects relating to that Right. The pertinence of this question is glimpsed in view of the broad society accession to the virtual life. It is used the hypothetical-deductive method. The research is theoretical, bibliographical and documentary.
\end{abstract}

Keywords: Alternative dispute resolution methods, Civil law procedure code, Access to justice

\footnotetext{
${ }^{1}$ Mestrando em Direito pela Universidade Nove de Julho - UNINOVE, São Paulo, (Brasil). Linha de Pesquisa Justiça e o Paradigma da Eficiência. Coordenador do Núcleo de Prática Jurídica da Universidade Nove de Julho - UNINOVE. E-mail: leandrolima@ aasp.org.br

${ }^{2}$ Mestrando em Direito pela Universidade Nove de Julho - UNINOVE, São Paulo, (Brasil). Linha de Pesquisa Justiça e o Paradigma da Eficiência. E-mail: felixfer@terra.com.br
} 


\section{INTRODUÇÃO.}

Este artigo discutirá o emprego dos métodos alternativos de resolução de controvérsias (ADR's) na perspectiva do Novo Código de Processo Civil e terá como referencial teórico a noção de Acesso à Justiça como direito à ordem jurídica justa.

As questões a se perquirir adiante versam acerca das possibilidades de utilização pela jurisdição das ferramentas virtuais de resolução alternativa de controvérsias (ODR's), proporcionadas pelas tecnologias da informação, para maximização dos efeitos atinentes àquele direito. Justificam-se estas indagações em virtude da ampla adesão da sociedade à vida que se desenvolve nos meios virtuais (como chats, redes sociais, aplicativos para smartphones de troca instantânea de mensagens, etc.).

Para enfrentar o mote desta análise, porém, parece necessário apresentar como antecedente o que se compreende por Acesso à Justiça e, assim, delinear-se-á os contornos teóricos da compreensão do direito a uma ordem jurídica justa, que não parece poder confundirse com a simples chance de ingresso ou exercício do direito de ação.

Importará, ainda, buscar compreender em que paradigma nos coloca o legislador em 2015, com o advento do Novo Código de Processo Civil, pois as alterações foram substanciais no que tange ao mister deste trabalho.

Antes de concluir será de igual relevo abordar doutrinariamente os métodos alternativos de resolução de controvérsias e, ainda, explicitar os modelos que se tem verificado, especialmente no âmbito privado, de exercício auto compositivo por meios virtuais.

$\mathrm{Na}$ realização desta proposta, empregar-se-á o método de abordagem hipotéticodedutivo e a pesquisa se desenvolverá por meio de investigação teórica, mediante revisão bibliográfica de artigos e livros que abordam os assuntos aqui circunscritos e, também, pela documentação direta, em virtude do estudo direto em fonte primária (texto legislativo).

\subsection{ACESSO À JUSTIÇA: O DIREITO A UMA ORDEM JURÍDICA JUSTA.}

Coisa curiosa de se notar é que, à exata medida em que alguém se torne um jurista (ou seja, que se gradue em Direito, curse uma especialização, um mestrado, um doutorado etc.), mais se evite o emprego de expressões como "justiça", salvo para se referir corriqueiramente ao Poder Judiciário (CAPPELLETTI; GARTH, 1988, p. 3), "isto é justo", "tal situação não é 
justa" ou congêneres, normalmente empregadas quase que com certa veemência pelo ingressante no curso de Direito.

O que na maior parte dos casos se ouve do jurista são locuções do tipo: "isto é inconstitucional”, "tal situação afronta a lei”, “esta ideia é contrária ao ordenamento", entre outras possíveis. Esta apreciação simplória, que se constata nas mais comezinhas conversações, é sintomática do tratamento pouco profundo que, no mais das vezes, se dispensa à noção de acesso à justiça.

A compreensão de acesso à justiça em um país de redemocratização recente como o Brasil parece levar muito tempo para superar a barreira da simples possibilidade de exercer o abstrato, autônomo, público e subjetivo direito de ação - tão automaticamente definível pelo mais jejuno segundo-anista. Acesso, nestes termos, talvez nunca se tenha de todo negado (ao menos não na história republicana do nosso país) e, obviamente, em regra, consoante ao mundo do dever ser.

\subsection{Acesso à justiça como Direito Humano e não como Mero Ingresso}

O significado de acesso à justiça que aqui se pretende explorar irá além do que a mera chance de propor ou contestar uma ação perante o sistema judicial formalmente instituído, denominado Poder Judiciário, cuja missão entende-se que deva ser, em verdade, a promoção de resultados individual e socialmente justos (CAPPELLETTI; GARTH, 1988, p. 4), pois, nos dizeres de Kazuo Watanabe:

\footnotetext{
A problemática do acesso à justiça não pode ser estudada nos acanhados limites do acesso aos órgãos judiciais já existentes. Não se trata apenas de possibilitar o acesso à Justiça, enquanto instituição estatal, e sim de viabilizar o acesso à ordem jurídica justa. Uma empreitada assim ambiciosa requer, antes de mais nada, uma nova postura mental (WATANABE, 988, p. 128).
}

Este acesso, então, só pode significar mais do que a viabilidade fática de valer-se do poder jurisdicional - faculdade esta que, aqui, entende-se como uma etapa possível do exercício do direito a uma ordem jurídica justa. Ela simboliza apenas o exercer do direito de acesso à justiça, naquele sentido costumeiro, de Poder Judiciário que vai decidir um conflito. Todavia, concebe-se que maximização do direito a uma ordem jurídica justa pode ocorrer também por outras vias. 
Uma visão da qual não se pode passar ao largo neste estudo refere-se às muitas modificações de base pelas quais tem passado a própria teoria do Estado e, por via reflexa, o Poder Judiciário.

Vive-se uma efervescência de relativizações em termos de território, soberania e povo. Basta que se observe com a mais superficial das atenções para questões como as dos refugiados (sejam os de conflitos bélicos como os de catástrofes ambientais), a falência da identificação ideológica e da legitimidade na representação democrática nos países do hemisfério norte, a fuga de muitos povos rumo aos localismos paralela aos mais impensáveis universalismos, a troca ininterrupta de informações pelas mídias sociais entre as pessoas comuns de forma horizontal e sem qualquer ingerência e controle (seja estatal, econômico, jornalístico ou de nenhuma ordem), etc.

Esta era de flexibilidade é classificada de várias formas e adquire muitos contornos, conforme a teorização que a observe. Mas, seja como modernidade líquida (BAUMAN, 2001), como modernidade tardia (GIDDENS, 1991) ou, ainda, como modernidade reflexiva (BECK,1998), notas distintivas dos nossos tempos são a pluralidade, a rapidez e a inevitabilidade.

Nesse sentido, não se pode mais olvidar que os Estados não existem mais em torno de seu próprio eixo (se é que se possa afirmar que tal situação já ocorreu).

Nem parece mais cabível à esta altura dos acontecimentos um debate acerca de que posições possam ocupar normas internacionais no ordenamento ' $x$ ' ou ' $y$ ', porque isto será simples decisão política estatal inscrita em constituições, muitas vezes afrouxada por seus próprios tribunais constitucionais na via interpretativa, sendo que, da observância fática e geral, o que hodiernamente ocorre é a busca por um alinhamento das ordens jurídicas às decisões que os próprios Estados tomam na esfera internacional - daí poder-se falar com clareza e tranquilidade em direito à ordem jurídica justa como Direito Humano.

Fora de dúvida que será plausível objetar-se que não está inscrito em tratado internacional um Direito Humano o direito ao acesso a uma ordem jurídica justa e que, nem mesmo os Estados na gestação destes tratados chegaram a aventar a possibilidade deste direito, sendo ele até o presente uma construção doutrinária.

Ocorre que, a concepção teórica com a qual se olha para o implemento de Direitos Humanos neste trabalho não requer que eles estejam escritos em nenhum tratado ou mesmo que eles tenham sido pensados por quem os instituiu. 
Isto porque, tais direitos, com o decorrer do tempo e o surgimento de mudanças no mundo e na sociedade, acabam por ser complementados e reforçados sob uma nova ótica, envolvendo-se, assim, num processo contínuo de gestação, que se pode classificar como dinamogênico (SILVEIRA; ROCASOLANO, 2010).

Assim sendo, o direito à ordem jurídica justa pode ser visto na esfera global de tutela dos direitos da pessoa no art. $8^{\circ}$ da Declaração Universal dos Direitos Humanos, que reconhece a faculdade individual de recorrer à jurisdição de seu país na busca de sanar violações aos seus direitos legais ou constitucionais.

No mesmo passo, da tutela protetiva da pessoa em âmbito global, é o art. $2^{\circ}$, item 3 , do Pacto Internacional sobre Direitos Civis e Políticos de 1966 (Decreto n 592/62), voltado à prestação jurisdicional, ao exercício geral do direito de petição perante os poderes públicos e a garantia do efetivo cumprimento das decisões judiciais. Com maior especificidade quanto às garantias judiciais penais, cuja gravidade em razão da potencial ingerência no status libertatis reclama disposição própria, há no mesmo tratado o art. 14, versando acerca das tradicionais medidas relativas à prisão, não autoincriminação, presunção de inocência, etc.

Do extrato regional dos direitos da pessoa, a Convenção Americana de Direitos Humanos (Pacto de San Jose da Costa Rica - Decreto nº 678/92) parece emblemático notar a disposição do art. $2^{\circ}$, que determina a adoção de disposições no ordenamento interno capazes de realizar os direitos nela previstos. Só por este ponto de vista, já seria bastante interessante avaliar a instituição do novo Código de Processo Civil.

Diversamente do Pacto global, a Convenção regional engloba as garantias judiciais penais e não penais em um só dispositivo, o art. $8^{\circ}$, sendo seu item 1 aquele que pode ser apontado como continente do direito à ordem jurídica justa.

\subsection{Acesso à Justiça como Direito Fundamental.}

Da Constituição Federal de 1988 é possível realizar uma depreensão do direito à ordem jurídica justa pela exegese de vários dispositivos.

Contudo, mesmo sendo autônomos os direitos e garantias fundamentais contidos entre os incisos do art. $5^{\circ}$, como o direito de acesso à informações de interesse público (XXXIII), o direito de petição (XXXIV, $a$ ), o princípio da indeclinabilidade da jurisdição (XXXV), o devido processo legal (LIV), o princípio da publicidade dos atos processuais (LX), a assistência judiciária gratuita (LXXIV) e a razoável duração do processo (LXXVIII), por muito que se 
possa entender como imediatamente óbvio, eles se mostram mais como facetas do direito a uma ordem jurídica justa.

Porque será o respeito conjunto a todos estes direitos em um processo, resultante num máximo possível de pacificação, com o menos possível de dissabores que um litígio possa causar, que poderá realizar o direito à ordem jurídica justa - a qual, preferencialmente, se realizaria antes dele, isto é, se ele tivesse sido evitado.

Assim, este direito em si parece resultar da conjugação de disposições mais abrangentes da Constituição, a começar pela sua declaração de intenções, consubstanciada no preâmbulo constitucional: o anúncio da justiça como um valor supremo é de se levar em consideração, pois, inobstante este trecho não seja dotado de coercibilidade, sua presença no texto não pode ser negligenciada, servindo a propósitos interpretativos.

O próprio postulado do Estado Democrático de Direito, insculpido no art. $1^{\circ}$ da $\mathrm{CF}$, traz em seu âmago a necessidade de convivência em uma ordem jurídica justa, pois nele não se busca tão somente a mera igualdade formal perante a lei, mas sim a igualdade material, que seja capaz de conferir a todos as reais possibilidades de fruir dos mesmos status numa determinada ordem social.

A manifestação do norte interpretativo de toda a nossa Constituição - o fundamento da dignidade da pessoa humana - revela-se do modo mais nítido quando se observa que a busca pela jurisdição pode ser entendida como um dos passos que se possa percorrer no caminho do exercício do direito à ordem jurídica justa.

O cidadão, quando tem seus direitos violados (e, portanto, sua dignidade ferida em alguma de suas projeções), buscará a jurisdição. Exercido o caminhar deste passo no direito de acesso à justiça, no sentido de Poder Judiciário (o ingresso), resta ainda todo um iter a se percorrer entre esta chegada às portas do Poder Judiciário e a garantia da devolução ou reparação do bem da vida que fora violado.

Este percurso, tendo em vista todas as suas possíveis intercorrências e não somente seu resultado final, é que define se a ordem jurídica é ou não justa. Qualquer conflito já é, per se, desagradável. Não é preciso que a ordem jurídica o torne ainda mais gravoso. Pouco é necessário, assim, para que se anteveja que, quanto menos “passos” sejam necessários, mais a ordem jurídica justa se realiza. 


\subsection{NOVO CÓDIGO DE PROCESSO CIVIL: UMA (RE)LEITURA DO LITÍGIO.}

Seja o Código de Processo Civil recém promulgado, seja o anterior, ou qualquer outro diploma legal, em matéria de interpretação e aplicação, imperiosas se fazem duas análises: uma que seja situacional e outra que seja sistêmica.

Isto significa que o operador do Direito deve compreender qualquer ramo da ciência jurídica tanto com relação ao mundo do ser quanto ao mundo do dever ser nos quais aquele ramo se insere.

É dizer: o Direito em questão deve ser interpretado e aplicado tendo em mente as contingências históricas, as aspirações e o jogo de forças em vigor na sociedade em que se pretenda fazer valer; deve, também, ser considerado no plexo do ordenamento em que se insira, e não somente segundo os próprios postulados do âmbito dogmático que integre, conjugandose aos demais princípios e regras presentes em seu entorno imediato e mediato - o que, no caso do processo civil, significa não somente o direito civil, empresarial e das relações de consumo, senão também (e com muita força) o direito constitucional e o direito internacional dos direitos humanos.

A colocação destas duas lentes, sobrepostas, na frente da visão do operador do Direito quando se volta ao objeto "processo civil" resulta numa releitura que muito interessa aos fins do direito a uma ordem jurídica justa: parece que começamos a caminhar para menos litígio e mais pacificação.

\subsection{Processo é Fim em Si Mesmo?}

Os direitos processuais (civil, penal, trabalhista, etc.), enquanto ciências, sofreram com certa relegação a segundo plano por algum tempo no âmbito do estudo das disciplinas dogmáticas e, posteriormente, dada o significativo processo de especialização e autonomização pelo qual passaram os campos do conhecimento humano de um modo geral, esse caráter de simples acessoriedade foi suplantado, tornando-se o estudo do direito processual tão "ramo do direito" quanto aquele âmbito dogmático que o originou.

Pelo prisma acadêmico e docente entende-se que esta especialização pelo menos a priori seja desejável porque, para a pesquisa, é relevante conseguir delimitar o objeto da investigação com a maior acuidade possível, ao passo que, para o ensino, importa muito que haja clareza na definição dos princípios, conceitos e institutos próprios de cada disciplina - isto tudo, é claro, sem prejuízo das frutíferas experiências que possam resultar de convergências e/ou dissensos 
interdisciplinares, mas que só serão possíveis depois da perquirição ou apreensão nas ciências em apartado.

Contudo, outra coisa completamente distinta do que se pratica na academia e no ensino jurídicos é a elaboração legislativa e o que, a partir dela, se faz na atividade jurisdicional nestas duas últimas, a relação entre direito ' $x$ ' e direito processual ' $x$ ' segue outra lógica: a de instrumentalidade.

Processo não é fim em si mesmo. Processo por si só nem existe, fisicamente o que ainda há (e certamente por pouco tempo!) são autos. É ideia pura, pois trata-se de abstração que significa, em regra, uma representação mental humana de atos encadeados numa organização predisposta conforme à lei (ou seja, que, em dado momento, combinamos todos juntos a respeitar, nas pessoas de nossos representantes) para resolver o famoso conflito de interesses qualificado por uma pretensão resistida, cujo objetivo seja um provimento jurisdicional final.

Para que serve esta representação ou, melhor dizendo, qual vem a ser sua finalidade é o que realmente importa, pois este é o fim que se consegue vislumbrar para o próprio Direito: a obtenção de algum nível satisfatório de pacificação social, o alcance de uma convivência sadia entre as pessoas, o bem-estar em comunidade na maior medida possível, enfim, aquela palavra que sempre estamos evitando - a realização do sentimento de justiça.

Assim, não sendo possível dentro da ótica constitucional presente enxergar o processo como um fim em si mesmo, do qual não se possa tirar os olhos, nem o juiz um ente sagrado com o qual tenhamos que viver a cuidar para manter conosco sua boa disposição (KAFKA, 2008, p.186), vejamos como se descortina o novo processo civil constitucionalizado.

\subsection{As Aspirações no Novo Código de Processo Civil (Lei $\mathbf{n}^{0}$ 13.105, de 16 de março de 2015).}

Raras são as oportunidades que tiveram ou terão os juristas em seu tempo de vivenciarem a alteração de uma lei da importância do Código de Processo Civil, porque as implicações desta norma não se referem apenas ${ }^{1}$ à aplicação do direito privado, havendo reflexos, em maior ou menor medida, para todo o direito processual lato sensu. A sedimentação desta norma na sociedade, na doutrina e na jurisprudência poderá levar anos, senão décadas.

\footnotetext{
${ }^{1}$ Como se de pouca monta fosse.
} 
Assim, constituiria ousadia risível pretender tecer as mais elaboradas conjecturas sobre o novo Código, fazer os mais agudos comentários doutrinários ou criar as mais disparatadas teorias sobre algo que nem se começou a sentir o sabor.

Todavia, para os fins deste trabalho, nem seriam necessárias tais aventuras, porque, o que se está a investigar é o direito a uma ordem jurídica justa em sua relação com a minimização dos litígios, tendo em vista a aplicação dos métodos alternativos de resolução de controvérsias, vislumbrando-se, ainda, as possibilidades no que tange à aplicação destes métodos em ambientes virtuais - neste sentido, conhecer os "porquês" do novo CPC, mediante a análise de sua Exposição de Motivos (NUNES, 2015, pp.19-35), já é um espaço pelo qual se possa começar a tatear, mesmo que no escuro.

Neste passo, o primeiro parágrafo da Exposição de Motivos do novo codex é merecedor de transcrição, pois o que se alega ali é um porquê de vulto:

Um sistema processual civil que não proporcione à sociedade o reconhecimento e a realização dos direitos, ameaçados ou violados, que têm cada um dos jurisdicionados, não se harmoniza com as garantias constitucionais de um Estado Democrático de Direito.

Uma das justificativas dadas para a alteração de toda a lei foi o paulatino enfraquecimento de coesão havido em virtude das sucessivas reformas pelas quais o Código anterior passou, afirmando-se que a visão central fora a busca da eficiência para o novo diploma, visando gerar um processo mais célere, justo e voltado às necessidades sociais.

Assim, a própria Exposição de Motivos no Novo Código de Processo Civil apresenta os cinco objetivos que embasaram a elaboração de seu anteprojeto, organizando toda a construção do próprio texto justificativo em torno deles.

Os objetivos enunciados são (NUNES, 2015, p.22): 1) estabelecer expressa e implicitamente verdadeira sintonia fina com a Constituição Federal; 2) criar condições para que o juiz possa proferir decisão de forma mais rente à realidade fática subjacente à causa; 3 ) simplificar, resolvendo problemas e reduzindo a complexidade de subsistemas, como, por exemplo, o recursal; 4) dar todo o rendimento possível a cada processo em si mesmo considerado; e, 5) finalmente, sendo talvez este último objetivo parcialmente alcançado pela realização daqueles mencionados antes, imprimir maior grau de organicidade ao sistema, dandolhe, assim, mais coesão.

Parece, numa lida de relance, que o Novo Código de Processo Civil se propõe a realizar uma ordem jurídica justa. Mas é claro que, sabidamente, não são legislações que, isoladamente 
consideradas, realizam direitos. É necessário que muitos outros esforços sejam envidados para que isto ocorra, afinal, se simples fosse a transposição da norma para vida, talvez elas nem precisassem ser escritas, discutidas ou mesmo estudadas.

O que se está a dizer, em verdade, é que as aspirações que permeiam o Novo Código de Processo Civil trazem consigo uma onda favorecedora, ou seja, é momento propício para a discussão das necessidades reais atinentes ao próprio processo, às ritualísticas forenses, ao exercício mítico do poder jurisdicional, à cultura social do demandismo, ao grau de importância que se deva conferir à autonomia dos indivíduos em resolverem seus próprios problemas, ao nível de disponibilidade de determinados direitos em algumas circunstâncias, etc.

\subsection{Artigo 334 do Novo Código de Processo Civil: Alteração do Procedimento Comum no Processo de Conhecimento.}

Na sistemática do procedimento comum ordinário do Código de 1973, tudo se iniciava pela disposição do art. 285, CPC/73, pois, estando presentes os requisitos do art. 282, CPC/73, necessários à petição inicial, despachava o juiz para que fosse citado o réu. E assim formava-se a relação processual. Daí por diante, era possível que houvesse uma audiência preliminar se os direitos envolvidos admitissem conciliação (art. 331, CPC/73) ou, não havendo, mais uma tentativa deveria ser feita (arts. 447 ao 449, CPC/73) posteriormente na audiência instrutória, em que efetivamente fosse ser julgada a lide.

Percebe-se então que, as partes vinham ao processo para brigar e a lei lhes facultava, por alguns instantes (alguns minutos, o tempo de o juiz fazer a pergunta), a oportunidade de tentarem se resolver ou de, no calor dos ânimos, continuarem brigando.

É como se fosse dito ao litigante: você estaria disposto a ceder um pouco em sua posição e tentar se colocar por um minuto no lugar do seu oponente? Ou você prefere aceitar os cinquenta por cento de chance de que aquele (a) senhor (a), magistrado (a), simbolizando todo o poder do Estado diga bem na face do seu desafeto que, em todos esses anos do processo tramitando, era você quem tinha razão? Quem vem para uma briga está mais predisposto à qual das duas opções?

O Novo Código de Processo Civil tentará inverter esta lógica, que por pouco já não obrigava os juízes a quase chantagearem as partes com a ameaça da própria morosidade do sistema judicial para aceitarem conciliações. Ainda não se sabe dos resultados, claro. 
O autor de uma ação, na nova sistemática aponta na petição inicial (assim como o réu, em manifestação escrita), se não desejar que seja empregado o método de auto composição em seu processo. Ou seja, a auto composição é o “passo um”, a primeira via eleita pelo legislador, não se realizando apenas se as partes manifestarem expressamente seu desinteresse em contrário ou se os interesses em jogo forem daqueles que inadmitem a metodologia.

Desse modo, é o réu citado para audiência de conciliação ou mediação, que pode ocorrer em mais de uma sessão (o número de sessões será aquele correspondente ao necessário à composição das partes), sendo conduzida por juiz ou, onde houver, por conciliador ou mediador.

A seriedade que o legislador imprime às partes para o procedimento fica muito clara pela maneira como melhor se entende algo quando o assunto é direito patrimonial: o não comparecimento sem justificativa é ato que atenta contra a dignidade da justiça e resulta em multa de até dois por cento da vantagem econômica pretendida ou do valor da causa, revertida em favor da União ou do Estado.

Podem ser constituídos pelas partes representantes com poderes para negociar e transigir, sendo imprescindível a presença de seus advogados ou defensores públicos. Se a auto composição for bem-sucedida, reduz-se a avença a termo e homologa-se por sentença.

Observe-se que, mesmo não havendo o entendimento entre as partes neste momento e, prosseguindo normalmente o processo, ainda na audiência de instrução e julgamento, mais uma vez o juiz tentará compor os litigantes, por expressa disposição do art. 359, do Novo Código de Processo Civil, mesmo que tenham sido empregados anteriormente e sem êxito outros métodos de solução consensual de conflitos.

\subsection{MEIOS ALTERNATIVOS DE RESOLUÇÃO DE CONTROVÉRSIAS E MITIGAÇÃO DA LITIGÂNCIA: UM CAMINHO MAIS CURTO RUMO À ORDEM JURÍDICA JUSTA?}

Quando se fala em "meios alternativos” a primeira questão que surge é, aparentemente, a mais simples: alternativos em relação a quê? Ora, a resposta não pode parecer outra que não ao Estado. Mas, veja-se que a própria justiça estatal nasce como uma alternativa: uma alternativa à força.

Em regra, antes do monopólio estatal da produção e aplicação do Direito, que se consolidam com o Estado Moderno, o que havia eram ou a lei do mais forte ou a autotutela; naquela imperava a convenção e, nesta, a auto composição. Assim, a unificação territorial e a 
centralização do poder, em oposição a fragmentariedade do poder feudal no medievo, fundaram as bases sobre as quais se erigiu o regime de liberdades públicas do homem moderno. Entretanto, já se comentou, esta construção tem sofrido abalos.

Aponta Gorczevski (1999, pp.28) que o Estado contemporâneo tem perdido organicidade enquanto sistema jurídico, tendo colapsado o próprio constitucionalismo em razão da superação no equilíbrio dos poderes e, fora isso, o ente soberano tem agora de lidar com os influxos globalizatórios e a expansão de um direito comercial paralelo ao que vigora internamente.

O Poder Judiciário em si mesmo enfrenta uma crise sem precedentes, cujas raízes Bacellar (2011, pp.31-37) localiza em tópicos como o próprio ensino jurídico que é ministrado aos futuros operadores do Direito (treinamos cães para a rinha!) é voltado para o sistema da contradição, dos lados polarizados, do modelo firmemente adversarial, cuja visão é exclusivamente focada no pedido - o autor identifica isto com uma incompreensão real dos interesses, inapta ao alcance da pacificação social, posto que coloque fim apenas à lide processual, mas não à lide sociológica.

Em tal cenário seria natural que alternativas aparecessem. E é neste estado da arte que os métodos auto compositivos retomam força.

\subsection{Alternative Dispute Resolution (ADR): Os Meios Alternativos de Resolução de Controvérsias.}

O termo em inglês vem da sistematicidade com que foram organizados e estudados os métodos pela corrente de Critical Legal Studies, dos anos de 1970, na Universidade estadunidense de Harvard.

Houve à época uma grande crise no sistema judicial daquele país, decorrente da complexidade das matérias enfrentadas pelo poder judiciário, da ampla busca judicial de proteção aos direitos civis, da alta demanda em questões empresariais, ambientais e consumeristas, etc. Constatou-se um colapso nos órgãos civis e penais, pois faltavam maneiras de resolver os conflitos entre os particulares, assim como era incapaz o sistema de assegurar acesso a todos.

O uso destes métodos, de um modo geral, surge inicialmente no campo dos conflitos privados (direitos de cunho patrimonial, empresarial, famíliar, relações de vizinhança, conflitos 
entre Estados, etc.). Mas nada impede que sejam empregados por organizações públicas ou semi-públicas, como o próprio judiciário (tal qual prevê expressamente o NCPC), a Administração Pública, MP, defensorias, Procon, clubes, associações de bairros, centros comunitários, ministros religiosos, federações ou associações de empresas, sindicatos, etc.

Os meios alternativos se dividem em duas formas: auto compositivos (negociação, mediação e conciliação) ou heterocompositivos (arbitragem).

A negociação (GORCKZEVSKI, 1999, pp.24-26) é resultante de atividades livres e privadas, tendo aplicação comum em contratos, questões relacionadas ao estado civil (situação antenupcial), quitação de dívidas e pactos ou tratados internacionais. Costuma ser levada a efeito em ritmo de competição ou de colaboração, exercida pelas próprias partes envolvidas ou por um negociador (eleito ou especificamente contratado para este fim). A forma é combinada previamente e, normalmente, se dá pela exposição escrita de propostas.

A mediação (GORCKZEVSKI, 1999, pp.29-35), apesar de ser conduzida por um terceiro, continua sendo um método auto compositivo, pois ele é sujeito imparcial, que atua auxiliando às partes, isto é: são os envolvidos que chegarão à decisão, não o mediador. Portanto, na mediação, os próprios atores da discussão são a autoridade final do processo decisório.

Por isto que a mediação é aconselhável para aqueles casos em que a contenda envolve pessoas que tenham vínculos afetivos, em que o melhor a se buscar seja a preservação das relações, cujos caracteres essenciais são a voluntariedade, a rapidez, a economia, a informalidade, a autodeterminação e a possibilidade de uma visão de futuro às partes em conflito.

A conciliação (GARCEZ, 2004, pp.53-56) é também meio auto compositivo, todavia, nela a postura do terceiro envolvido é mais incisiva. Ele não é somente facilitador do diálogo, indo além, aconselhando as partes, tentando de modo mais ativo promover o entendimento.

Ambos os métodos são baseados na autodeterminação dos conflitantes, mas lançam mão de terceiros que agem como viabilizadores do desenlace da disputa, ainda que muito similares (até mesmo às vezes contíguos no mesmo procedimento), não são absolutamente iguais. A tênue distinção entre mediação e conciliação repousa na atuação do terceiro entre as partes.

Ao passo que na mediação o gerenciamento do diálogo e o abrandamento dos ânimos ocorrem mediante a escuta ativa pelo terceiro durante a exposição de posicionamentos das partes - de tal maneira que quase elas mesmas já atingem a resolução da disputa - na 
conciliação, o terceiro apresenta postura mais enfática sugerindo medidas, acenando para possibilidades, apresentando alternativas etc.

A arbitragem é, entre as ADR's, o método que mais se aproxima ao sistema adversarial de litígios comuns (GORCKZEVSKI, 1999, p.35). Mas, apesar desta característica heterocompositiva, a aceitação inicial em se obrigar mantém seus resultados distantes daqueles obtidos em provimentos jurisdicionais tradicionais.

Hermes Marcelo Huck (1994, p.101) bem observa a diferença psicológica que comparativamente existe entre os efeitos do processo judicial contencioso e o procedimento arbitral, pois "a vontade das partes se reúne ante um juízo muito especial, habilitado a conhecer questões comerciais (ou técnicas) específicas, dentro de um clima de discrição e sigilo".

A arbitragem é método heterocompositivo de resolução de conflitos, pois, submetendose as partes à convenção arbitral, a decisão exarada pelo terceiro eleito para dirimir a celeuma é obrigatória.

\subsection{Online Dispute Resolution (ODR): As Resoluções Alternativas de Controvérsias em Meios Virtuais.}

Embora não seja possível alegar-se a plena inclusão digital em um país de dimensões continentais como o Brasil (há ainda quem não saiba ler ou sequer tenha com o que se alimentar), pode-se encarar com certa amplitude o uso das tecnologias da informação por grandes contingentes populacionais.

A tendência ao descontentamento com a prestação jurisdicional é aumentar, ainda que ela melhorasse estratosfericamente em termos de celeridade e qualidade, porque a realidade das pessoas agora é a do click e esta realidade ainda não parece alcançável pelo Direito (seja em sua metodologia de elaboração, aplicação, estudo, interpretação, pesquisa, etc.) - sempre um passo atrás da sociedade, como nem poderia deixar de ser.

Assim, é provável que, mesmo com as disposições do NCPC, continuem a ganhar força mecanismos que vem crescendo em nosso país (ainda timidamente, mas já há empresas especializadas no ramo) conhecidos como ODR's. Observe-se que estes mecanismos começaram a ser usados para negócios celebrados online, mas agora as empresas que oferecem o serviço convidam as partes a trazerem suas controvérsias da vida real para serem solucionadas no meio virtual. 
A controvérsia continua sendo resolvida de modo alternativo em relação ao provimento jurisdicional final, proferido com carga decisória pelo magistrado. Mas, nesse caso, não haverá a homologação de termo por sentença. Há somente partes e terceiro.

E a questão sobre quem seja este terceiro é ainda mais instigante, pois nem sempre ele será uma pessoa natural. Em alguns modelos de ODR, pode ser que o mecanismo de debate entre posições das partes seja completamente automatizado e controlado por um software, um algoritmo de programação: há "mediação" online, só que sem mediador!

$\mathrm{Na}$ atualidade dois dos maiores exemplos que se podem mencionar de emprego das ODR's são o famoso website de compras E-Bay² e o mecanismo de pagamentos largamente utilizados por outros sítios eletrônicos $\mathrm{PayPal}^{3}$.

O que se verifica, portanto, é praticamente a expansão de uma cyber-justiça, que vem sendo exercida em paralelo aos judiciários dos Estados, ao revés dos ordenamentos jurídicos destes e com ampla adesão de imensos contingentes populacionais. $\mathrm{O}$ que pode o Direito fazer diante disto? Nada e, entende-se, que não se deve. O melhor que se pode fazer é tentar aprender com essas iniciativas e, aparentemente, o legislador vem tentando.

\subsection{Experiências legislativas para novos Fins Jurisdicionais sem Processo: Interface entre ADR e ODR.}

O Novo Código de Processo Civil, ao disciplinar sua modalidade de audiência preliminar no artigo 334 completamente revogadora da lógica anterior - permitia-se chegar ao front de batalha, para depois perguntar se os soldados estavam dispostos a baixar as armas - dispôs em seu $\S 7^{\circ}$ que a audiência de conciliação ou de mediação pode realizar-se por meio eletrônico, na forma da lei. No mesmo sentido é o art. 46 da nova Lei de Mediação, que menciona expressamente a possibilidade de realização do procedimento pela internet.

O Conselho Nacional de Justiça, para adequar a Política Judiciária Nacional de tratamento dos conflitos de interesses, reeditou a Resolução nº125 de 2010 pela Emenda $\mathrm{n}^{\circ} 2 / 2016$, incluindo uma série de disposições relacionadas tanto ao novo Código de Processo Civil, quanto à nova Lei de Mediação.

\footnotetext{
${ }^{2}$ Para conhecimento: http://pages.ebay.com/services/buyandsell/disputeres.html

${ }^{3}$ Para conhecimento: https://www.paypal.com/au/cgi-bin/webscr?cmd=xpt/cps/general/PPDisputeResolutionoutside
} 
Pela Resolução reeditada o CNJ se coloca claramente alinhado ao objetivo de promover ações de incentivo à auto composição de litígios e à pacificação social por meio da conciliação e da mediação, pretendendo fazê-lo com a participação de todos os órgãos do Poder Judiciário, entidades públicas e privadas em parcerias, abrangendo universidades e instituições de ensino.

Para tanto o CNJ visa criar um Sistema de Mediação e Conciliação Digital ou a distância para atuação pré-processual de conflito, que sirva especificamente aos fins da audiência preliminar do Novo Código de Processo Civil e do procedimento da nova Lei de Mediação, ao qual poderão aderir formalmente os Tribunais de Justiça e os Tribunais Regionais Federais.

\subsection{CONCLUSÕES.}

O estudo que aqui se empreendeu pelo método hipotético-dedutivo, mediante pesquisa teórica, bibliográfica e documental, enfrentou questões relativas ao emprego dos métodos alternativos de resolução de controvérsias (ADR's) sob o ponto de vista do Novo Código de Processo Civil, adotando a ideia de Acesso à Justiça como direito à ordem jurídica justa.

Explorou-se o tema da viabilidade do uso pelo Poder Judiciário dos modelos on line de resolução alternativa de controvérsias (ODR's), hodiernamente em ampla utilização no âmbito das negociações de direito privado, visando à máxima efetividade do direito à ordem jurídica justa.

Apresentou-se a noção de Acesso à Justiça apartada da simples possibilidade de ingresso ou mero exercício do direito de ação.

Estudaram-se as alterações do Novo Código de Processo Civil, promovendo-se uma análise da norma à luz da interpretação constitucional que se deva operar verticalmente em relação a todos os ramos do Direito, salientando-se a posição instrumental que o direito processual deve ocupar na realização dos direitos em si e na função do próprio Direito.

Foram explanados, ainda, alguns dos métodos alternativos de resolução de controvérsias e apresentadas novas ferramentas virtuais que se tem empregado no exercício auto compositivo de conflitos negociais online.

Desta feita, a indagação inicial acerca da utilização de meios alternativos de resolução de controvérsias (ADR/ODR), na perspectiva do Novo Código de Processo Civil, como forma de mitigar a litigância e ser um caminho mais célere rumo a à ordem jurídica justa, restou confirmada. 
Com efeito, as alterações paradigmáticas sinalizadas por este novo cenário são tais que, com as disposições do Novo Código de Processo Civil, não somente a faculdade decisória do Estado-juiz (outrora tão centralizadora) pode-se vislumbrar flexibilizada em favor do interesse maior das partes em razão de seu direito a uma ordem jurídica justa, como também, em virtude da ampla adesão social às tecnologias da informação, o próprio meio - isto é, o espaço - em que se desenvolve a decisão acerca da disputa pode vir a ser alterado.

Ou seja, além de não ser mais sempre o juiz quem efetivamente decide (com o emprego das ADR's), tal solução nem sempre se daria dentro do tradicional espaço de uma sala de audiências (no caso de se utilizar, em concomitância, a ideia de ODR).

Interessa, portanto, notar que, ainda assim, a atividade jurisdicional estatal não perde sua relevância, mas passa por uma relevante modificação, adquirindo novas feições, que merecem ser objeto ainda de profundas reflexões por parte de toda a comunidade jurídica.

É bastante interessante o que se verificou na parte final deste estudo, pois, em um primeiro momento narrou-se sobre uma cyber-justiça, valendo-se das ADR's e mimetizando a atuação estatal, sem, contudo, haver a possibilidade de o que nela ficar decidido ser reduzido a termo e homologado por sentença. Depois, em um segundo momento, o que se narra é a lei e o CNJ, também se valendo das ADR's e mimetizando a cyber-justiça, tendo, porém, a possibilidade de que aquilo que fica decidido seja reduzido a termo e homologado por sentença. O que será que as partes irão escolher? É mesmo questão de esperar para saber.

\section{REFERÊNCIAS}

ALEXY, Robert. Teoria dos direitos fundamentais. Tradução de Virgílio Afonso da Silva, São Paulo: Malheiros Editores, $2^{\mathrm{a}}$ ed., 2011.

BACELLAR, Roberto Portugal. O Poder Judiciário e o paradigma da guerra na solução dos conflitos. In: PELUSO, Antonio Cezar; RICHA, Morgana de Almeida. Conciliação e mediação: estruturação da política judiciária nacional. - Rio de Janeiro: Forense, 2011.

BARROSO, Luís Roberto. Interpretação e aplicação da Constituição: fundamentos de uma dogmática constitucional transformadora. São Paulo: Saraiva, 1996.

BAUMAN, Zygmunt. Modernidade líquida; tradução Plínio Dentzien. - Rio de Janeiro: Zahar, 2001.

BECK, Ulrich. La sociedad del riesgo: hacia una nueva modernidad. - Barcelona: Paidós, 1998. 

CAMBI, Eduardo. Neoconstitucionalismo e neoprocessualismo: direitos fundamentais, políticas públicas e protagonismo judiciário. São Paulo: Editora Revista dos Tribunais, 2009. Neoconstitucionalismo e neoprocessualismo. In: FUX, Luiz; NERY JR, Nelson; WAMBIER, Teresa Arruda Alvim. Processo e Constituição: estudos em homenagem ao professor José Carlos Barbosa Moreira. São Paulo: Editora Revista dos Tribunais,2006.

CANOTILHO, Joaquim José Gomes. Direito constitucional, Coimbra: Almedina, $5^{\circ}$ ed., 1991. CAPPELLETTI, Mauro; GARTH, Bryant: Acesso à justiça; tradução Ellen Gracie Northfleet. - Porto Alegre: Fabris Editor, 1988.

CARDOZO, José Eduardo. Prefácio. In: AISTON HENRIQUE DE SOUZA et al., 2013. Manual de mediação judicial. - Brasília: 2013.

CARNELUTTI, Francesco. Instituições do processo civil; tradução Adrián Sotero de Witt Batista. - Campinas: Servanda, 1999. Vol. I.

DE LUCCA, Newton, Aspectos jurídicos da contratação informática e telemática. - São Paulo: Saraiva, 2003.

DWORKIN, Ronald. Levando os direitos a sério. 1. ed. Tradução Jefferson Luiz Camargo. São Paulo: Martins Fontes, 2007.

FACCHINI NETO, Eugenio. Entrevista. Revista Multijuris: Primeiro grau em ação.

FALCÃO, Joaquim. Estratégias para a reforma do judiciário. In Reforma do Judiciário. Sergio Rabello Tamm Renault e Pierpaolo Bottini [coord.]. São Paulo: Saraiva, 2005.

FARIA, José Eduardo. Direito e justiça no século XXI: a crise da Justiça no Brasil. Coimbra/Portugal. Seminário Direito e Justiça no Século XXI, 2003, disponível em http://opj.ces.uc.pt/portugues/novidds/comunica/JoseEduarFaria.pdf. Acesso em 19.03.2015.

GARCEZ, José Maria Rossani. Negociação, ADR's, mediação, conciliação e arbitragem. 2.ed. rev. e ampl. - Rio de Janeiro: Lumen Iuris, 2004.

GIDDENS, Anthony. As consequências da modernidade; tradução Raul Filker. - São Paulo: Editora UNESP, 1991. - (Biblioteca básica).

GORCKZEVSKI, Clovis. Formas alternativas para resolução de conflitos. - Porto Alegre: Livraria do Advogado, 1999.

GUERRA FILHO, Willis Santiago. Processo constitucional e direitos Fundamentais, $2^{\circ} \mathrm{ed}$. São Paulo: Celso Bastos Editor: Publicação do Instituto Brasileiro de Direito Constitucional, 2001. 
HUCK. Hermes Marcelo. Sentença estrangeira e lex mercatoria: horizontes do comércio internacional. - São Paulo: Saraiva, 1994.

KAFKA, Franz. O processo. Organização, tradução, prefácio e notas Marcelo Backes. - Porto Alegre: L\&PM, 2008.

KATSH, Ethan; RABINOVICH-EINY, Orna. Digital justice - Reshaping boundaries in an online dispute resolution environment. International Journal of Online Dispute Resolution 2014 (1) 1. Disponível em 〈http://www.international-odr.com/first_issue $>$ Acesso em 23 de março de 2016.

MANCUSO, Rodolfo de Camargo. Acesso à justiça: condicionantes legítimas e ilegítimas. São Paulo: Editora Revista dos Tribunais, 2011.

,Rodolfo de Camargo A resolução dos conflitos e a função judicial no contemporâneo Estado de Direito. - São Paulo: Revista dos Tribunais, 2009.

MEYER-PFLUG, Samantha Ribeiro. BRAGA, Sergio Pereira. A jurisdição constitucional e a reforma do poder judiciário (EC n.45/04). São Paulo: Editora Revista dos Tribunais, impresso. V.1, 2011. O ativismo judicial e o conselho nacional de justiça. In Justiça e o paradigma da eficiência.Org. Adriana Silva Maillart, Mônica Bonetti Couto, Samantha Ribeiro Meyer-Pflug, Samyra Haydêe Dal Farra Naspolini Sanches. Coord. Vladmir Oliveira da Silveira e Orides Mezzaroba. São Paulo: Ed. Revista dos Tribunais, impresso. V.1, 2011.

NALINI, José Renato, “Do poder judiciário”. In. Constituição federal: avanços, contribuições e modificações no processo democrático brasileiro, coordenadores MARTINS, Ives Gandra; REZEK, Francisco. São Paulo: Revista dos Tribunais/ Centro de Extensão universitária, 2008. . Há esperança de justiça eficiente? In Justiça e o Paradigma da Eficiência. Org. Adriana Silva Maillart, Mônica Bonetti Couto, Samantha Ribeiro Meyer-Pflug, Samyra Haydêe Dal Farra Naspolini Sanches. Coord. Vladmir Oliveira da Silveira e Orides Mezzaroba. São Paulo. Ed. Revista dos Tribunais: 2011.

NUNES, Dierle. CPC referenciado - Lei 13.105/2015. - Florianópolis: Empório do Direito Editora, 2015.

SILVEIRA, Vladmir Oliveira da; ROCASOLANO, Maria Mendez. Direitos Humanos: Conceitos, significados e funções. - São Paulo: Saraiva, 2010. 
WATANABE, Kazuo. Acesso à justiça e sociedade moderna: Participação e processo. - São Paulo: Revista dos Tribunais, 1988. 